\title{
Adaptive mutability of colorectal cancers in response to targeted therapies
}

\author{
Mariangela Russo ${ }^{1,2 *}$, Giovanni Crisafulli ${ }^{1,2}$, Alberto Sogari ${ }^{1,2}$, Nicole M. Reilly ${ }^{3}$, Sabrina Arena ${ }^{1,2}$, Simona \\ Lamba $^{1}$, Alice Bartolini ${ }^{1}$, Vito Amodio ${ }^{1,2}$, Alessandro Magrì1,2, Luca Novara1 ${ }^{1}$, Ivana Sarotto ${ }^{1}, Z^{5 a c h a r y ~ D . ~}$ Nagel $^{4}$, \\ Cortt G. Piett ${ }^{4}$, Alessio Amatu ${ }^{5,6}$, Andrea Sartore-Bianchi ${ }^{5,6}$, , Salvatore Siena ${ }^{5,6}$, Andrea Bertotti, \\ Livio Trusolino ${ }^{1,2}$, Mattia Corigliano $^{7,8}$, Marco Gherardi $^{7,8}$, Marco Cosentino Lagomarsino $^{7,8}$, \\ Federica Di Nicolantonio ${ }^{1,2}$, Alberto Bardelli1, ${ }^{1 *}$
}

${ }^{1}$ Candiolo Cancer Institute, FPO-IRCCS, Candiolo (TO) 10060, Italy. ${ }^{2}$ Department of Oncology, University of Torino, Candiolo (TO) 10060, Italy. ${ }^{3}$ Fondazione Piemontese per la Ricerca sul Cancro ONLUS, Candiolo (TO) 10060, Italy. ${ }^{4}$ Department of Environmental Health, JBL Center for Radiation Sciences, Harvard T.H. Chan School of Public Health, Boston, MA 02115, USA. ${ }^{5}$ Niguarda Cancer Center, Grande Ospedale Metropolitano Niguarda, 20162 Milan, Italy. ${ }^{6}$ Department of Oncology and Hemato-Oncology, Università degli Studi di Milano, 20133 Milan, Italy. IFOM-FIRC Institute of Molecular Oncology, 20139 Milan, Italy. ${ }^{8}$ Department of Physics, Università degli Studi di Milano, and I.N.F.N., 20133 Milan, Italy.

*Corresponding author. Email: alberto.bardelli@unito.it (A.B.); mariangela.russo@unito.it (M.R.)

The emergence of drug resistance limits the efficacy of targeted therapies in human tumors. The prevalent view is that resistance is a fait accompli: when treatment is initiated, cancers already contain drug-resistant mutant cells. Bacteria exposed to antibiotics transiently increase their mutation rates (adaptive mutability), thus improving the likelihood of survival. We investigated whether human colorectal cancer (CRC) cells likewise exploit adaptive mutability to evade therapeutic pressure. We found that epidermal growth factor receptor (EGFR)/BRAF inhibition down-regulates mismatch repair (MMR) and homologous recombination (HR) DNA repair genes, and concomitantly up-regulates error-prone polymerases in drug-tolerant (persister) cells. MMR proteins were also down-regulated in patient-derived xenografts and tumor specimens during therapy. EGFR/BRAF inhibition induced DNA damage, increased mutability and triggered microsatellite instability. Thus, like unicellular organisms, tumor cells evade therapeutic pressures by enhancing mutability.

Over 75 years ago, Luria and Delbrück demonstrated that bacterial resistance to phage viruses was due to random mutations that spontaneously occurred in the absence of selection (1). Resistance to targeted therapies in human tumors is also widely thought to be due to mutations that exist prior to treatment (2). The conventional view is that relapses occur because drug-resistant mutant subclones are present in any detectable metastatic lesion prior to initiation of therapy. According to this view, resistance is a 'fait accompli', and the time to recurrence is merely the interval required for pre-existing drug resistant (mutant) cells to repopulate the lesion (3).

Here we explore the hypothesis that resistance to targeted therapies can also be fostered by a transient increase in genomic instability during treatment, leading to de novo mutagenesis. A similar process has been shown to increase the emergence of microbial strains resistant to antibiotics $(4,5)$. In a stable microenvironment, the mutation rate of microorganisms is usually low, which precludes the accumulation of deleterious mutations. However, several mechanisms of stress-induced genetic instability and increased mutability, known as stress-induced mutagenesis (SIM), have been described in bacteria and yeast (6-12).
Bacterial persister cells can survive lethal stress conditions imposed by antibiotics through a reduction in growth rate. A subsequent reduction in the efficiency of DNA mismatch repair (MMR) $(4,9,13)$, and a shift to error-prone DNA polymerases increases the rate at which adaptive mutations occur in the surviving population $(4,9,14,15)$. Selection then allows the growth of mutant subpopulations capable of replicating under stressful conditions. Once the stressed population has adapted to the new conditions, the hypermutator status is counter-selected to avoid accumulation of deleterious mutations and to prevent the continuous increase of mutational load $(9,16-20)$. Together, these processes boost genetic diversity, foster adaptability to new microenvironments and contribute to the development of resistance $(9,12$, 18, 19).

In the setting of cancer, the emergence of a drug tolerant persister population is often observed when oncogene-dependent tumor cells are challenged with targeted agents (21). Persister cancer cells survive exposure to targeted therapies through poorly understood mechanisms (21), and represent a reservoir from which genetically divergent, drug-resistant derivatives eventually emerge $(22,23)$. Recent work showed that drug-resistant mutant cancer cells can originate not only 
from rare, pre-existing mutant clones, but also from drug-tolerant sub-populations (24). The probability that the latter resistance mechanism occurs would be greatly increased if the genetic diversity of tumor cells was enhanced during treatment. Accordingly, we hypothesized that during the persister state tumor cells, like unicellular organisms, alter DNA repair and replication mechanisms to enhance adaptive mutability.

\section{Targeted therapy-induced down-modulation of MMR and HR proficiency of CRC cells}

To test our hypothesis, we studied the response of microsatellite stable (MSS) human colorectal cancer (CRC) cell lines to the anti-EGFR (epidermal growth factor receptor) antibody cetuximab, which is approved, together with panitumumab, for treatment of patients with metastatic CRC whose tumors lack $R A S$ and $B R A F$ mutations (25); or with BRAF inhibitor dabrafenib as combinatorial treatment, which has shown promising activity in patients with CRC harboring $B R A F$ mutations (26). We selected human CRC cell lines that are $R A S$ and $B R A F$ wild-type and sensitive to EGFR blockade (DiFi cells, fig. S1A), or that carry the oncogenic $B R A F$ p.V600E mutation and are sensitive to concomitant EGFR and BRAF inhibition (WiDr cells, fig. S1A). Treatment with targeted agents led to G1 cell cycle arrest (fig. S1B). However, a small number of drug-tolerant persister cells survived several weeks after treatment initiation (fig. S1, C and D). Indeed, when drug pressure was removed, these cells rapidly resumed growth and again showed sensitivity to targeted therapy, thus demonstrating that persisters are only transiently and reversibly resistant to the treatment (fig. S1, E and F). In contrast, prolonged treatment led to the generation of permanently resistant cells, which did not re-acquire sensitivity after removal of drug pressure (fig. S1, E and F).

We next assessed whether CRC cells modulate the expression of DNA repair genes upon drug treatment. Transcriptional profiles revealed decreased expression of the MMR genes $M L H 1, M S H 2, M S H 6$, as well as homologous recombination (HR) effectors, such as BRCA2 and RAD51 (Fig. 1A and fig. S1, G and H). Expression of EXO1, a gene coding for an exonuclease that participates in mismatch and double-strand break (DSB) repair, was also affected (Fig. 1A and fig. S1, G and $\mathrm{H}$ ). A time-dependent down-regulation of MMR and HR proteins was also observed (Fig. 1B and fig. S2, A and B). Comparable results were obtained in another cetuximab-sensitive human CRC cell line, NCIH508 (fig. S3, A to C), and in $B R A F$ mutant HT29 cells that were derived from the same patient from whom the WiDr cell line originated (fig. S3, D and E). Furthermore, we confirmed that down-regulation or loss of DNA repair components is maintained in persister cells (fig. S4, A to D). Therapy-induced modulation of DNA repair genes expression was transient and expression levels returned to normal upon removal of treatment (fig. S5A).
Cancer cells that had previously developed permanent resistance to targeted agents did not modulate expression of DNA repair genes in response to drugs (fig. S5, B and C).

To ascertain whether targeted therapies affect DNA repair competence in CRC cells, we used fluorescence-based multiplex host cell reactivation (FM-HCR) assays (27). CRC cells were transfected with a G:G mismatch-containing plasmid to determine the impact of drug treatment on MMR capacity. A MMR deficient (MMRd) human CRC cell line (LIM1215) was used as a positive control for MMR loss. We found that in CRC cells treated with targeted agents, MMR proficiency (MMRp) was reduced to levels comparable to those observed in LIM1215 (Fig. 1C and fig. S6A).

We next evaluated cellular HR capability by using the twostep, plasmid-based, pDRGFP/pCBASce-I assay (28). Upon stable expression of the pDRGFP plasmid, we measured the generation of a green fluorescent signal upon DSBs induced by Sce-I expression. By this assay, both DiFi and WiDr cells showed a marked reduction in HR proficiency upon treatment with targeted therapies (Fig. 1D and fig. S6B).

\section{MMR proteins are down-regulated in samples of CRC residual disease after targeted treatment}

To determine whether the cell-based findings extend to patient-derived tumor samples, we exploited our CRC biobank of molecularly and therapeutically annotated patient-derived xenograft (PDX) models $(29,30)$. We selected six MSS PDX models with wild-type $K R A S, N R A S$ and $B R A F$ in which EGFR inhibition by cetuximab led to tumor regression to a variable extent, paralleling the clinical scenario (Fig. 2A). Immunohistochemistry analysis unveiled areas with down-regulation of MLH1 and/or MSH2 in all neoplastic samples obtained when tumors were at the point of maximum response to cetuximab, but still contained residual persisters (Fig. 2, B and C, and fig. S7, A to D), as compared with placebo-treated controls.

We next investigated whether down-regulation of DNA repair proteins also occurs in clinical specimens from two CRC patients who achieved an objective partial response upon treatment with FOLFOX plus panitumumab. In both instances, tumor specimens were longitudinally collected at diagnosis and at maximal therapeutic response, when a limited number of tumor cells persist despite treatment. MLH1 and MSH2 were down-regulated in tumor samples obtained at response compared to pre-treatment specimens, confirming the clinical relevance of our findings (Fig. 2D).

\section{Induction of DNA damage and error-prone DNA poly- merases in CRC cells treated with targeted therapies}

In addition to reduced DNA repair ability, we found that targeted therapies triggered a switch from high-fidelity to lowfidelity DNA polymerases. DNA polymerases usually involved 
in accurate DNA replication, such as POL $\delta$ and POL $\varepsilon$ were down-regulated; whereas DNA polymerases characterized by poor accuracy, low processivity and absence of proofreading capacity (i.e., error-prone polymerases) were induced (Fig. 1A and fig. S4A). These included Pol $\iota$, Polk, and Rev1 (which belong to $\mathrm{Y}$ family polymerases, orthologous to the bacterial stress-induced polymerases Pol IV and Pol V), as well as Pol $\lambda$ and Pol $\mu$, (31) (Fig. 1, A and B, and figs. S1, G and H; S2B; S3, $\mathrm{B}$ to $\mathrm{C}$ and $\mathrm{E}$; and S4, A and D). Error-prone polymerases replace canonical high-fidelity polymerases that stall when encountering a DNA lesion, and facilitate DNA replication across DNA damage sites in a manner that introduces errors into the genome $(15,16,20)$; this may lead to bases mispairings, incorporation of aberrant DNA primer ends, and increased mutagenesis rate $(32,33)$.

We therefore investigated whether treatment with targeted therapies leads to genomic damage in cancer cells, and if error-prone mediated repair of DNA damage was favored when CRC cells encountered the hostile environment imposed by targeted therapies. Indeed, quantification of phosphorylation of H2AX at Ser $139(\gamma \mathrm{H} 2 \mathrm{AX})$, a common marker of DNA damage (34), revealed a dose- and time-dependent increase in the number of foci-positive nuclei upon drug treatment (Fig. 3, A and B, and fig. S8, A and B), while no further increase was observed in permanently resistant cells upon drug treatment (fig. S8, C and D). In addition, we observed a dose- and time-dependent increase in the number of 53BP1-positive nuclei upon EGFR and BRAF blockade (fig. S9, $\mathrm{A}$ and $\mathrm{B})$. In direct opposition to BRCA1, 53BP1 promotes nonhomologous end joining (NHEJ)-mediated DSB repair while preventing HR through restriction of end resection (35). These data suggest that targeted therapies trigger a switch from high-fidelity to error-prone mediated repair of DNA damage, thereby potentially increasing the occurrence of mutations conferring drug resistance.

We next explored the possible causes of the DNA damage observed upon targeted therapies administration. While several chemotherapeutic agents directly generate DNA damage, drugs interfering with oncogenic signaling (such as EGFR or BRAF inhibitors) are not directly genotoxic. Intriguingly, however, it has been shown that certain targeted therapies, such as ABL and BRAF inhibitors, increase the levels of reactive oxygen species (ROS) in cancer cells $(36,37)$, potentially contributing to DNA damage during treatment. ROS levels significantly increased when CRC cells were exposed to EGFR and BRAF inhibitors (Fig. 3C). In contrast, ROS levels were not increased in permanently drug-resistant (adapted) cells upon drug treatment (fig. S9C).

The drug-induced increase in ROS levels was abrogated when targeted therapies were administered in the presence of the antioxidant N-acetyl-L-cysteine (NAC) (Fig. 3C). NAC administration partially reduced the number of $\curlyvee \mathrm{H} 2 \mathrm{AX}$ foci- positive nuclei upon EGFR and BRAF blockade (fig. S10, A and B). However, co-treatment with NAC did not prevent or rescue down-regulation of DNA repair genes (fig. S10C). Notably, addition of NAC delayed onset of relapse to targeted therapies when administered together with MAPK pathway inhibitors (fig. S10, D and E) $(38,39)$.

\section{Interfering with oncogenic dependencies initiates stress response in CRCs}

To elucidate the mechanistic basis of therapy-induced mutagenesis in cancer cells, we tested whether the adaptive mutability that we observed in response to targeted therapies was simply a secondary response to G1 cell cycle arrest or DNA damage, or whether it represented an active stress-response. We found that thymidine-mediated cell cycle stress (fig. S11, A to C) or direct DNA damage with the alkylating agent oxaliplatin (fig. S11, D to F) rather promoted up-regulation of the MMR and HR repair systems (fig. S11, C and F); while G1 cell cycle arrest by nutrient starvation did not lead to modulation of DNA repair gene expression (fig. S11, G to I). In bacterial cells, both the DNA damage-activated SOS response and the general stress response appear to be required to induce adaptive mutagenesis (14). We therefore examined the modulation of the kinase mammalian target of rapamycin (mTOR), which is a master regulator of mammalian cellular stress response (40). Indeed, the mTOR effectors pS6K-p70K were down-regulated with kinetics comparable to that of MMR and HR modulation, upon EGFR and BRAF pharmacological blockade (Fig. 3D). However, silencing of mTOR did not affect expression of DNA repair proteins or $\gamma \mathrm{H} 2 \mathrm{AX}$ (Fig. 3E). It is therefore plausible that down-regulation of mTOR contributes to stress-induced mutagenesis of cancer cells but is not sufficient to activate this phenotype.

The exquisite sensitivity of DiFi and WiDr cells to EGFR and BRAF blockade reflects cell-specific oncogenic alterations. The EGFR locus is amplified in DiFi cells (2); the WiDr cells carry the $B R A F$ p.V600E oncogenic mutation, but they also become dependent on feedback activation of EGFR when treated with BRAF inhibitors (41). We therefore assessed whether interfering with the oncogenic dependency of cancer cells could directly initiate the drug-induced stress phenotype. Indeed, siRNA-mediated knock-down of EGFR or KRAS in DiFi cells, and $B R A F(+/-E G F R)$ in WiDr cells led to reduced expression of DNA repair proteins, triggered DNA damage and mTOR down-modulation (Fig. 3E), and increased ROS levels (fig. S12). These results exclude the possibility that drug-induced down-modulation of DNA repair pathways could be due to a nonspecific (off-target) effect of the anti-EGFR antibody cetuximab or the BRAF inhibitor dabrafenib. 
Targeted therapies induce adaptive mutability in CRC cells

Next, we tested whether the stress response induced by targeted therapies translated into increased mutagenesis in CRC cells. We used a reporter assay in which a dinucleotide CArepeat microsatellite drives the NanoLuc enzyme coding sequence out-of-frame (Fig. 4A). Random mutations that introduce frameshifts in this region, in absence of a functional MMR, would restore the NanoLuc open reading frame leading to bioluminescence. Analogous approaches have previously been used to measure MMR defects in cancer cells (4244). To validate the assay, we first introduced the CANanoLuc vector into a MMRd human CRC cell line (HCT116) and three MMRp human CRC cell lines (DiFi, WiDr, NCIH508). The NanoLuc signal was significantly higher in MMRd cells after 48 hours of standard growth conditions (Fig. 4B). This difference was further increased when HCT116 were kept in culture for several days, while the signal in the MMRp lines remained low (Fig. 4B), indicating that the CANanoLuc assay effectively detects MMR deficiency in cancer cells.

We next used the CA-NanoLuc system to measure the impact of ectopic inactivation of MMR in CRC cells. To this end, we used CRISPR-CAS9 to inactivate the $M L H 1$ gene in HT29 human CRC cell line. After the isolation of two independent $M L H 1$ knock-out (KO) clones (fig. S13, A and B), they were transduced with the CA-NanoLuc vector. MLH1 KO clones exhibited higher levels of NanoLuc signal as expected, confirming that the assay can detect inactivation of DNA MMR (Fig. 4C). Next, drug-dependent (transient) MMR down-regulation was evaluated. EGFR and BRAF inhibition led to time-dependent increases of bioluminescence (Fig. 4D), paralleling the down-regulation of DNA repair effectors and up-regulation of low-fidelity polymerases. We further found that permanently resistant derivatives no longer exhibited adaptive mutability in response to targeted therapies (fig. S14).

\section{Genomic alterations in CRC cells upon treatment with targeted therapies}

To determine whether molecular evidence of adaptive mutability was present in the genome of CRC cells treated with EGFR and BRAF inhibitors, we analyzed whole-exome sequencing (WES) data from DiFi and WiDr parental, persister, and drug-resistant derivative cells. The overall mutational burden (number of mutations/megabase) of persisters, and drug resistant cell population was only marginally affected (fig. S15, A and B). As a control, we assessed whether MMR permanent inactivation, induced by $M L H 1 \mathrm{KO}$, affected the mutational burden of HT29 CRC cells, and found that it was only marginally affected (fig. S16A).

We therefore changed approach. Since treatment with targeted therapies led to a transient MMR deficient phenotype, we reasoned that MMR status could be more easily detected by examining microsatellite regions, where DNA replication slippage errors occur frequently and are ineffectively repaired in the absence of MMR. Indeed, WES analysis unveiled alterations in microsatellite regions of HT29 in which the MLH1 gene was genetically knocked-out (fig. S16, B and C). Importantly, we also detected increased genetic instability in the microsatellite regions of CRC cells made resistant to targeted agents (Fig. 5, A and B), as shown by a shift in the length of microsatellite regions, highlighting the impact of targeted therapies on DNA repair process and mutagenicity. To detect the occurrence of microsatellite alterations in nonclonal cell populations, we utilized a high depth capture panel that detects hotspot somatic variants as well as shifts in length of microsatellite regions. Indeed, such high sensitivity analysis unveiled a significant shift in the length of microsatellite regions in both persister and drug-resistant cells (Fig. 5C and fig. S17).

We next assessed the impact of targeted therapies on the genomic landscape of PDXs. To do this, we studied a PDX (CRC0078) (Fig. 2A and fig. S7D) that was continuously treated with cetuximab until it developed resistance (fig. S18). WES analysis of the cetuximab-resistant tumor tissue revealed alterations in microsatellite genomic regions which were not present in the PDX tumor collected from the corresponding untreated mouse (Fig. 5, D and E). Overall, these results indicate that CRC cells and a CRC PDX exposed to targeted therapies experience loss of replication fidelity in regions of nucleotide repeats.

\section{Discussion}

The development of resistance has emerged as a major limitation of targeted therapies directed against oncoproteins, such as EGFR, BRAF and ABL (25).

In this study, we tested the hypothesis that cancer cells treated with targeted therapies activate stress-induced mutagenic mechanisms. We found that persister (drug-tolerant) cancer cells that survive EGFR and/or BRAF inhibition exhibit DNA damage, down-regulate mismatch and homologous recombination repair proteins, switch from high-fidelity to error-prone DNA repair, and transiently increase their mutagenic ability.

Stress-induced mutagenesis is a characteristic trait of unicellular organisms to transiently accelerate genetic diversity, in a fraction of the population, when encountering a hostile environment. (16). Indeed, we found that therapy-induced modulation of DNA repair in cancer cells is also transitory and reverts back once a mutational landscape able to restore the ability to grow in the presence of the drug is achieved. We postulate that in cells of multicellular organisms, stress-induced mutagenesis is not operational. However, in cancer cells that have lost tissue-imposed homeostasis, and in many 
ways operate like unicellular organisms, this ancestral program is still available and is unleashed by oncoprotein-targeted drugs. A similar process has also been observed in cancer cells undergoing hypoxia-driven stress $(7,45,46)$.

The analysis of mutational signatures has emerged as a valuable tool to document the mutational processes operative in cells (47). In future studies, it will be interesting to establish whether specific mutational signatures emerge under targeted therapies. Resolving such processes, which we postulate occur transiently in small cell subpopulations, is likely to require extensive genomic comparisons of multiple clones and independent datapoints.

These results may have clinical implications. The knowledge that cancer cells under therapeutic stress downregulate key effectors of the DNA repair machinery, such as MMR and HR, exposes a vulnerability that could be clinically exploited. For example, it will be important to assess whether down-regulation of HR proteins confers sensitivity to polyADP-ribose polymerases (PARP) inhibitors as observed in HR deficient cancers (48-50). Moreover, pharmacological or genetic interference could be deployed to curb the cellular mechanisms that initiate drug-driven adaptive mutagenesis with the goal of reducing the generation of new variants during treatment. This strategy could potentially increase and prolong the clinical efficacy of targeted therapies.

\section{REFERENCES AND NOTES}

1. S. E. Luria, M. Delbrück, Mutations of bacteria from virus sensitivity to virus resistance. Genetics 28, 491-511 (1943). Medline

2. S. Misale, R. Yaeger, S. Hobor, E. Scala, M. Janakiraman, D. Liska, E. Valtorta, R. Schiavo, M. Buscarino, G. Siravegna, K. Bencardino, A. Cercek, C.-T. Chen, S. Veronese, C. Zanon, A. Sartore-Bianchi, M. Gambacorta, M. Gallicchio, E. Vakiani, V. Boscaro, E. Medico, M. Weiser, S. Siena, F. Di Nicolantonio, D. Solit, A. Bardelli, Emergence of KRAS mutations and acquired resistance to anti-EGFR therapy in colorectal cancer. Nature 486, 532-536 (2012). doi:10.1038/nature11156 Medline

3. L. A. Diaz Jr., R. T. Williams, J. Wu, I. Kinde, J. R. Hecht, J. Berlin, B. Allen, I. Bozic, J. G. Reiter, M. A. Nowak, K. W. Kinzler, K. S. Oliner, B. Vogelstein, The molecular evolution of acquired resistance to targeted EGFR blockade in colorectal cancers. Nature 486, 537-540 (2012). doi:10.1038/nature11219 Medline

4. A. Gutierrez, L. Laureti, S. Crussard, H. Abida, A. Rodríguez-Rojas, J. Blázquez, Z. Baharoglu, D. Mazel, F. Darfeuille, J. Vogel, I. Matic, $\beta$-Lactam antibiotics promote bacterial mutagenesis via an RpoS-mediated reduction in replication fidelity. Nat. Commun. 4, 1610 (2013). doi:10.1038/ncomms2607 Medline

5. H. Long, S. F. Miller, C. Strauss, C. Zhao, L. Cheng, Z. Ye, K. Griffin, R. Te, H. Lee, C.C. Chen, M. Lynch, Antibiotic treatment enhances the genome-wide mutation rate of target cells. Proc. Natl. Acad. Sci. U.S.A. 113, E2498-E2505 (2016). doi:10.1073/pnas.1601208113 Medline

6. I. Bjedov, O. Tenaillon, B. Gérard, V. Souza, E. Denamur, M. Radman, F. Taddei, I. Matic, Stress-induced mutagenesis in bacteria. Science 300, 1404-1409 (2003). doi:10.1126/science.1082240 Medline

7. D. M. Fitzgerald, P. J. Hastings, S. M. Rosenberg, Stress-induced mutagenesis: Implications in cancer and drug resistance. Annu. Rev. Cancer Biol. 1, 119-140 (2017). doi:10.1146/annurev-cancerbio-050216-121919 Medline

8. P. L. Foster, Stress-induced mutagenesis in bacteria. Crit. Rev. Biochem. Mol. Biol. 42, 373-397 (2007). doi:10.1080/10409230701648494 Medline

9. R. S. Galhardo, P. J. Hastings, S. M. Rosenberg, Mutation as a stress response and the regulation of evolvability. Crit. Rev. Biochem. Mol. Biol. 42, 399-435 (2007). doi:10.1080/10409230701648502 Medline
10. E. Shor, C. A. Fox, J. R. Broach, The yeast environmental stress response regulates mutagenesis induced by proteotoxic stress. PLOS Genet. 9, e1003680 (2013). doi:10.1371/journal.pgen.1003680 Medline

11. E. Heidenreich, Adaptive mutation in Saccharomyces cerevisiae. Crit. Rev. Biochem. Mol. Biol. 42, 285-311 (2007). doi:10.1080/10409230701507773 Medline

12. D. M. Fitzgerald, S. M. Rosenberg, What is mutation? A chapter in the series: How microbes "jeopardize" the modern synthesis. PLOS Genet. 15, e1007995 (2019) doi:10.1371/journal.pgen.1007995 Medline

13. G. P. Rodriguez, N. V. Romanova, G. Bao, N. C. Rouf, Y. W. Kow, G. F. Crouse, Mismatch repair-dependent mutagenesis in nondividing cells. Proc. Natl. Acad Sci. U.S.A. 109, 6153-6158 (2012). doi:10.1073/pnas.1115361109 Medline

14. R. G. Ponder, N. C. Fonville, S. M. Rosenberg, A switch from high-fidelity to errorprone DNA double-strand break repair underlies stress-induced mutation. Mol. Cell 19, 791-804 (2005). doi:10.1016/j.molcel.2005.07.025 Medline

15. G. J. McKenzie, S. M. Rosenberg, Adaptive mutations, mutator DNA polymerases and genetic change strategies of pathogens. Curr. Opin. Microbiol. 4, 586-594 (2001). doi:10.1016/S1369-5274(00)00255-1 Medline

16. P. L. Foster, Adaptive mutation: Implications for evolution. BioEssays 22, 10671074 (2000). doi:10.1002/1521-1878(200012)22:12 < 1067:AlDBIES4>3.0.C0:2-Q Medline

17. F. Taddei, M. Radman, J. Maynard-Smith, B. Toupance, P. H. Gouyon, B. Godelle, Role of mutator alleles in adaptive evolution. Nature 387, 700-702 (1997) doi:10.1038/42696 Medline

18. J. Torkelson, R. S. Harris, M. J. Lombardo, J. Nagendran, C. Thulin, S. M. Rosenberg, Genome-wide hypermutation in a subpopulation of stationary-phase cells underlies recombination-dependent adaptive mutation. EMBO J. 16, 33033311 (1997). doi:10.1093/emboj/16.11.3303 Medline

19. W. A. Rosche, P. L. Foster, The role of transient hypermutators in adaptive mutation in Escherichia coli. Proc. Natl. Acad. Sci. U.S.A. 96, 6862-6867 (1999) doi:10.1073/pnas.96.12.6862 Medline

20. G. J. McKenzie, R. S. Harris, P. L. Lee, S. M. Rosenberg, The SOS response regulates adaptive mutation. Proc. Natl. Acad. Sci. U.S.A. 97, 6646-6651 (2000). doi:10.1073/pnas.120161797 Medline

21. S. V. Sharma, D. Y. Lee, B. Li, M. P. Quinlan, F. Takahashi, S. Maheswaran, U. McDermott, N. Azizian, L. Zou, M. A. Fischbach, K.-K. Wong, K. Brandstetter, B. Wittner, S. Ramaswamy, M. Classon, J. Settleman, A chromatin-mediated reversible drug-tolerant state in cancer cell subpopulations. Cell 141, 69-80 (2010). doi:10.1016/j.cell.2010.02.027 Medline

22. G. R. Oxnard, The cellular origins of drug resistance in cancer. Nat. Med. 22, 232234 (2016). doi:10.1038/nm.4058 Medline

23. M. Ramirez, S. Rajaram, R. J. Steininger, D. Osipchuk, M. A. Roth, L. S. Morinishi, L. Evans, W. Ji, C.-H. Hsu, K. Thurley, S. Wei, A. Zhou, P. R. Koduru, B. A. Posner, L. F. Wu, S. J. Altschuler, Diverse drug-resistance mechanisms can emerge from drug-tolerant cancer persister cells. Nat. Commun. 7, 10690 (2016). doi:10.1038/ncomms10690 Medline

24. A. N. Hata, M. J. Niederst, H. L. Archibald, M. Gomez-Caraballo, F. M. Siddiqui, H. E. Mulvey, Y. E. Maruvka, F. Ji, H. E. Bhang, V. Krishnamurthy Radhakrishna, G. Siravegna, H. Hu, S. Raoof, E. Lockerman, A. Kalsy, D. Lee, C. L. Keating, D. A. Ruddy, L. J. Damon, A. S. Crystal, C. Costa, Z. Piotrowska, A. Bardelli, A. J. lafrate, R. I. Sadreyev, F. Stegmeier, G. Getz, L. V. Sequist, A. C. Faber, J. A. Engelman, Tumor cells can follow distinct evolutionary paths to become resistant to epidermal growth factor receptor inhibition. Nat. Med. 22, 262-269 (2016). doi:10.1038/nm.4040 Medline

25. S. Misale, F. Di Nicolantonio, A. Sartore-Bianchi, S. Siena, A. Bardelli, Resistance to anti-EGFR therapy in colorectal cancer: From heterogeneity to convergent evolution. Cancer Discov. 4, 1269-1280 (2014). doi:10.1158/2159-8290.CD-140462 Medline

26. S. Kopetz, A. Grothey, R. Yaeger, E. Van Cutsem, J. Desai, T. Yoshino, H. Wasan, F. Ciardiello, F. Loupakis, Y. S. Hong, N. Steeghs, T. K. Guren, H.-T. Arkenau, P. Garcia-Alfonso, P. Pfeiffer, S. Orlov, S. Lonardi, E. Elez, T.-W. Kim, J. H. M. Schellens, C. Guo, A. Krishnan, J. Dekervel, V. Morris, A. Calvo Ferrandiz, L. S. Tarpgaard, M. Braun, A. Gollerkeri, C. Keir, K. Maharry, M. Pickard, J. ChristyBittel, L. Anderson, V. Sandor, J. Tabernero, Encorafenib, binimetinib, and cetuximab in BRAF V600E-mutated colorectal cancer. N. Engl. J. Med. 381, 1632 
1643 (2019). doi:10.1056/NEJMoa1908075 Medline

27. Z. D. Nagel, C. M. Margulies, I. A. Chaim, S. K. McRee, P. Mazzucato, A. Ahmad, R. P. Abo, V. L. Butty, A. L. Forget, L. D. Samson, Multiplexed DNA repair assays for multiple lesions and multiple doses via transcription inhibition and transcriptional mutagenesis. Proc. Natl. Acad. Sci. U.S.A. 111, E1823-E1832 (2014) doi:10.1073/pnas.1401182111 Medline

28. A. J. Pierce, R. D. Johnson, L. H. Thompson, M. Jasin, XRCC3 promotes homologydirected repair of DNA damage in mammalian cells. Genes Dev. 13, 2633-2638 (1999). doi:10.1101/gad.13.20.2633 Medline

29. A. Bertotti, E. Papp, S. Jones, V. Adleff, V. Anagnostou, B. Lupo, M. Sausen, J. Phallen, C. A. Hruban, C. Tokheim, N. Niknafs, M. Nesselbush, K. Lytle, F. Sassi, F. Cottino, G. Migliardi, E. R. Zanella, D. Ribero, N. Russolillo, A. Mellano, A. Muratore, G. Paraluppi, M. Salizzoni, S. Marsoni, M. Kragh, J. Lantto, A. Cassingena, Q. K. Li, R. Karchin, R. Scharpf, A. Sartore-Bianchi, S. Siena, L. A. Diaz Jr., L. Trusolino, V. E. Velculescu, The genomic landscape of response to EGFR blockade in colorectal cancer. Nature 526, 263-267 (2015). doi:10.1038/nature14969 Medline

30. C. Isella, F. Brundu, S. E. Bellomo, F. Galimi, E. Zanella, R. Porporato, C. Petti, A. Fiori, F. Orzan, R. Senetta, C. Boccaccio, E. Ficarra, L. Marchionni, L. Trusolino, E. Medico, A. Bertotti, Selective analysis of cancer-cell intrinsic transcriptional traits defines novel clinically relevant subtypes of colorectal cancer. Nat. Commun. 8 15107 (2017). doi:10.1038/ncomms15107 Medline

31. A. J. Rattray, J. N. Strathern, Error-prone DNA polymerases: When making a mistake is the only way to get ahead. Annu. Rev. Genet. 37, 31-66 (2003). doi:10.1146/annurev.genet.37.042203.132748 Medline

32. V. M. Krutiakov, Eukaryotic error prone DNA polymerases: Suggested roles in replication, repair and mutagenesis [in Russian]. Mol. Biol. (Mosk.) 40, 3-11 (2006). Medline

33. M. F. Goodman, Error-prone repair DNA polymerases in prokaryotes and eukaryotes. Annu. Rev. Biochem. 71, 17-50 (2002). doi:10.1146/annurev.biochem.71.083101.124707 Medline

34. L. J. Mah, A. El-Osta, T. C. Karagiannis, gammaH2AX: A sensitive molecular marker of DNA damage and repair. Leukemia 24, 679-686 (2010). doi:10.1038/leu.2010.6 Medline

35. S. Panier, S. J. Boulton, Double-strand break repair: 53BP1 comes into focus. Nat. Rev. Mol. Cell Biol. 15, 7-18 (2014). doi:10.1038/nrm3719 Medline

36. G. Cesi, G. Walbrecq, A. Zimmer, S. Kreis, C. Haan, ROS production induced by BRAF inhibitor treatment rewires metabolic processes affecting cell growth of melanoma cells. Mol. Cancer 16, 102 (2017). doi:10.1186/s12943-017-0667-y Medline

37. M. Koptyra, R. Falinski, M. O. Nowicki, T. Stoklosa, I. Majsterek, M. NieborowskaSkorska, J. Blasiak, T. Skorski, BCR/ABL kinase induces self-mutagenesis via reactive oxygen species to encode imatinib resistance. Blood 108, 319-327 (2006). doi:10.1182/blood-2005-07-2815 Medline

38. M. L. Sagristá, A. E. García, M. A. De Madariaga, M. Mora, Antioxidant and prooxidant effect of the thiolic compounds $\mathrm{N}$-acetyl-L-cysteine and glutathione against free radical-induced lipid peroxidation. Free Radic. Res. 36, 329-340 (2002). doi:10.1080/10715760290019354 Medline

39. E. D. Chan, D. W. Riches, C. W. White, Redox paradox: Effect of N-acetylcysteine and serum on oxidation reduction-sensitive mitogen-activated protein kinase signaling pathways. Am. J. Respir. Cell Mol. Biol. 24, 627-632 (2001). doi:10.1165/aircmb.24.5.4280 Medline

40. R. A. Saxton, D. M. Sabatini, mTOR signaling in growth, metabolism, and disease. Cell 168, 960-976 (2017). doi:10.1016/j.cell.2017.02.004 Medline

41. A. Prahallad, C. Sun, S. Huang, F. Di Nicolantonio, R. Salazar, D. Zecchin, R. L. Beijersbergen, A. Bardelli, R. Bernards, Unresponsiveness of colon cancer to BRAF(V600E) inhibition through feedback activation of EGFR. Nature 483, 100 103 (2012). doi:10.1038/nature10868 Medline

42. J. Shen, Z. Ju, W. Zhao, L. Wang, Y. Peng, Z. Ge, Z. D. Nagel, J. Zou, C. Wang, P. Kapoor, X. Ma, D. Ma, J. Liang, S. Song, J. Liu, L. D. Samson, J. A. Ajani, G.-M. Li, H. Liang, X. Shen, G. B. Mills, G. Peng, ARID1A deficiency promotes mutability and potentiates therapeutic antitumor immunity unleashed by immune checkpoint blockade. Nat. Med. 24, 556-562 (2018). doi:10.1038/s41591-018-0012-z Medline

43. N. Chatterjee, Y. Lin, B. A. Santillan, P. Yotnda, J. H. Wilson, Environmental stress induces trinucleotide repeat mutagenesis in human cells. Proc. Natl. Acad. Sci.
U.S.A. 112. 3764-3769 (2015). doi:10.1073/pnas.1421917112 Medline

44. R. Parsons, G.-M. Li, M. J. Longley, W. H. Fang, N. Papadopoulos, J. Jen, A. de la Chapelle, K. W. Kinzler, B. Vogelstein, P. Modrich, Hypermutability and mismatch repair deficiency in RER+ tumor cells. Cell 75, 1227-1236 (1993). doi:10.1016/0092-8674(93)90331-J Medline

45. V. T. Mihaylova, R. S. Bindra, J. Yuan, D. Campisi, L. Narayanan, R. Jensen, F. Giordano, R. S. Johnson, S. Rockwell, P. M. Glazer, Decreased expression of the DNA mismatch repair gene Mlh1 under hypoxic stress in mammalian cells. Mol. Cell. Biol. 23, 3265-3273 (2003). doi:10.1128/MCB.23.9.3265-3273.2003 Medline

46. R. S. Bindra, P. M. Glazer, Co-repression of mismatch repair gene expression by hypoxia in cancer cells: Role of the Myc/Max network. Cancer Lett. 252, 93-103 (2007). doi:10.1016/j.canlet.2006.12.011 Medline

47. M. Petljak, L. B. Alexandrov, J. S. Brammeld, S. Price, D. C. Wedge, S. Grossmann, K. J. Dawson, Y. S. Ju, F. Iorio, J. M. C. Tubio, C. C. Koh, I. Georgakopoulos-Soares, B. Rodríguez-Martín, B. Otlu, S. O'Meara, A. P. Butler, A. Menzies, S. G. Bhosle, K. Raine, D. R. Jones, J. W. Teague, K. Beal, C. Latimer, L. O'Neill, J. Zamora, E. Anderson, N. Patel, M. Maddison, B. L. Ng, J. Graham, M. J. Garnett, U. McDermott, S. Nik-Zainal, P. J. Campbell, M. R. Stratton, Characterizing mutational signatures in human cancer cell lines reveals episodic APOBEC mutagenesis. Cell 176, 12821294.e20 (2019). doi:10.1016/i.cell.2019.02.012 Medline

48. L. Li, H. Wang, E. S. Yang, C. L. Arteaga, F. Xia, Erlotinib attenuates homologous recombinational repair of chromosomal breaks in human breast cancer cells. Cancer Res. 68, 9141-9146 (2008). doi:10.1158/0008-5472.CAN-08-1127 Medline

49. S. Nowsheen, J. A. Bonner, A. F. Lobuglio, H. Trummell, A. C. Whitley, M. C. Dobelbower, E. S. Yang, Cetuximab augments cytotoxicity with poly (adp-ribose) polymerase inhibition in head and neck cancer. PLOS ONE 6, e24148 (2011). doi:10.1371/journal.pone.0024148 Medline

50. J. Mateo, C. J. Lord, V. Serra, A. Tutt, J. Balmaña, M. Castroviejo-Bermejo, C. Cruz, A. Oaknin, S. B. Kaye, J. S. de Bono, A decade of clinical development of PARP inhibitors in perspective. Ann. Oncol. 30, 1437-1447 (2019). doi:10.1093/annonc/mdz192 Medline

51. M. Russo, S. Lamba, A. Lorenzato, A. Sogari, G. Corti, G. Rospo, B. Mussolin, M. Montone, L. Lazzari, S. Arena, D. Oddo, M. Linnebacher, A. Sartore-Bianchi, F. Pietrantonio, S. Siena, F. Di Nicolantonio, A. Bardelli, Reliance upon ancestral mutations is maintained in colorectal cancers that heterogeneously evolve during targeted therapies. Nat. Commun. 9, 2287 (2018). doi:10.1038/s41467-01804506-z Medline

52. G. Germano, S. Lamba, G. Rospo, L. Barault, A. Magrì, F. Maione, M. Russo, G. Crisafulli, A. Bartolini, G. Lerda, G. Siravegna, B. Mussolin, R. Frapolli, M. Montone, F. Morano, F. de Braud, N. Amirouchene-Angelozzi, S. Marsoni, M. D'Incalci, A. Orlandi, E. Giraudo, A. Sartore-Bianchi, S. Siena, F. Pietrantonio, F. Di Nicolantonio, A. Bardelli, Inactivation of DNA repair triggers neoantigen generation and impairs tumour growth. Nature 552, 116-120 (2017). doi:10.1038/nature24673 Medline

53. K. Wang, D. Singh, Z. Zeng, S. J. Coleman, Y. Huang, G. L. Savich, X. He, P. Mieczkowski, S. A. Grimm, C. M. Perou, J. N. MacLeod, D. Y. Chiang, J. F. Prins, J. Liu, MapSplice: Accurate mapping of RNA-seq reads for splice junction discovery. Nucleic Acids Res. 38, e178 (2010). doi:10.1093/nar/gkq622 Medline

54. B. Li, C. N. Dewey, RSEM: Accurate transcript quantification from RNA-Seq data with or without a reference genome. BMC Bioinformatics 12, 323 (2011). doi:10.1186/1471-2105-12-323 Medline

55. J. Harrow, A. Frankish, J. M. Gonzalez, E. Tapanari, M. Diekhans, F. Kokocinski, B. L. Aken, D. Barrell, A. Zadissa, S. Searle, I. Barnes, A. Bignell, V. Boychenko, T. Hunt, M. Kay, G. Mukherjee, J. Rajan, G. Despacio-Reyes, G. Saunders, C. Steward, R. Harte, M. Lin, C. Howald, A. Tanzer, T. Derrien, J. Chrast, N. Walters, S. Balasubramanian, B. Pei, M. Tress, J. M. Rodriguez, I. Ezkurdia, J. van Baren, M. Brent, D. Haussler, M. Kellis, A. Valencia, A. Reymond, M. Gerstein, R. Guigó, T. J. Hubbard, GENCODE: The reference human genome annotation for The ENCODE Project. Genome Res. 22, 1760-1774 (2012). doi:10.1101/gr.135350.111 Medline

56. A. Gnirke, A. Melnikov, J. Maguire, P. Rogov, E. M. LeProust, W. Brockman, T. Fennell, G. Giannoukos, S. Fisher, C. Russ, S. Gabriel, D. B. Jaffe, E. S. Lander, C. Nusbaum, Solution hybrid selection with ultra-long oligonucleotides for massively parallel targeted sequencing. Nat. Biotechnol. 27, 182-189 (2009). 
doi:10.1038/nbt.1523 Medline

57. G. Siravegna, L. Lazzari, G. Crisafulli, A. Sartore-Bianchi, B. Mussolin, A. Cassingena, C. Martino, R. B. Lanman, R. J. Nagy, S. Fairclough, G. Rospo, G. Corti, A. Bartolini, P. Arcella, M. Montone, F. Lodi, A. Lorenzato, A. Vanzati, E. Valtorta, G. Cappello, A. Bertotti, S. Lonardi, V. Zagonel, F. Leone, M. Russo, A. Balsamo, M. Truini, F. Di Nicolantonio, A. Amatu, E. Bonazzina, S. Ghezzi, D. Regge, A. Vanzulli, L. Trusolino, S. Siena, S. Marsoni, A. Bardelli, Radiologic and genomic evolution of individual metastases during HER2 blockade in colorectal cancer. Cancer Cell 34 , 148-162.e7 (2018). doi:10.1016/j.ccell.2018.06.004 Medline

58. G. Corti, A. Bartolini, G. Crisafulli, L. Novara, G. Rospo, M. Montone, C. Negrino, B. Mussolin, M. Buscarino, C. Isella, L. Barault, G. Siravegna, S. Siena, S. Marsoni, F. Di Nicolantonio, E. Medico, A. Bardelli, A genomic analysis workflow for colorectal cancer precision oncology. Clin. Colorectal Cancer 18, 91-101.e3 (2019). doi:10.1016/j.clcc.2019.02.008 Medline

59. B. Niu, K. Ye, Q. Zhang, C. Lu, M. Xie, M. D. McLellan, M. C. Wendl, L. Ding, MSIsensor: Microsatellite instability detection using paired tumor-normal sequence data. Bioinformatics 30, 1015-1016 (2014). doi:10.1093/bioinformatics/btt755 Medline

60. S. R. Kennedy, M. W. Schmitt, E. J. Fox, B. F. Kohrn, J. J. Salk, E. H. Ahn, M. J. Prindle, K. J. Kuong, J.-C. Shen, R.-A. Risques, L. A. Loeb, Detecting ultralowfrequency mutations by Duplex Sequencing. Nat. Protoc. 9, 2586-2606 (2014). doi:10.1038/nprot.2014.170 Medline

61. M. W. Schmitt, E. J. Fox, M. J. Prindle, K. S. Reid-Bayliss, L. D. True, J. P. Radich, L. A. Loeb, Sequencing small genomic targets with high efficiency and extreme accuracy. Nat. Methods 12, 423-425 (2015). doi:10.1038/nmeth.3351 Medline

\section{ACKNOWLEDGMENTS}

We thank members of Molecular Oncology Laboratory at Candiolo Cancer Institute for critically reading the manuscript. We also thank A. Cassingena and F. Sassi for their help with experiments. We also thank Grahame Mckenzie for the NanoLuc plasmid design. Funding: The research was supported by Fondazione AIRC under 5 per Mille 2018 - ID. 21091 program - P.I. Bardelli Alberto, G.L. Siena Salvatore, G.L. Bertotti Andrea, G.L Trusolino Livio, G.L. Di Nicolantonio Federica; AIRC 2010 Special Program Molecular Clinical Oncology 5 per mille, Project n. 9970 Extension program (A.B.); AIRC IG n. 16788 (A.B.); AIRC IG 2018 - ID. 21923 project - PI Bardelli Alberto (A.B.); H2020 grant agreement no. 635342-2 MoTriColor (A.B.); Ministero Salute, Ricerca Corrente 2019 RC2019 (A.B.); H2020 grant agreement no. 754923 COLOSSUS (L.T.). A.B. has received research funding from PhoreMost and NeoPhore. Author contributions: M.R. and A.B. conceived the study. M.R., A.S., N.M.R., S.A., S.L., V.A., A.M. M.C., M.G. and M.C.L. conducted the experiments and analyzed data. G.C. performed NGS and bioinformatics analysis. Ali.B. performed NGS panel-based experiments. L.N. performed RNAseq bioinformatics analysis. N.Z. and C.P. provided plasmids harboring DNA damage. And.B. and L.T. analyzed and provided PDX material. I.S. performed and analyzed IHC data; A.A., A.S.B. and S.S. provided patient samples. F.D.N. analyzed data. M.R. and A.B. wrote the manuscript. A.B. supervised the study. Competing interests: L.T. is a paid consultant for Eli Lilly, AstraZeneca, and Merck KGaA. ZDN is an inventor on a patent (U.S. 9,938,587) covering methods and kits for determining DNA repair capacity. A.B. is a member of the scientific advisory board of NeoPhore and a shareholder of NeoPhore and PhoreMost. The other authors declare no competing interests. Data and materials availability: The FM-HCR reporter plasmids are available from ZDN under a Material Transfer Agreement. The pDRGFP and the pCBASce-I plasmids are available from AddGene under a Material Transfer Agreement. The NanoLuc expressing plasmid is available from PhoreMost Ltd (Cambridge, UK) under a Material Transfer Agreement. The HT29 Empty and MLH1 knock-out cells are available from AB (UNITO) under a Material Transfer Agreement. RNAseq data and DNA seq data are deposited in ENA (from EBI) - \#PRJEB28674.

\section{SUPPLEMENTARY MATERIALS}

science.sciencemag.org/cgi/content/full/science.aav4474/DC1 Materials and Methods

Figs. S1 to S18

Tables S1 and S2

References (51-61)

21 September 2018; resubmitted 24 July 2019

Accepted 26 October 2019

Published online 7 November 2019

10.1126/science.aav4474 

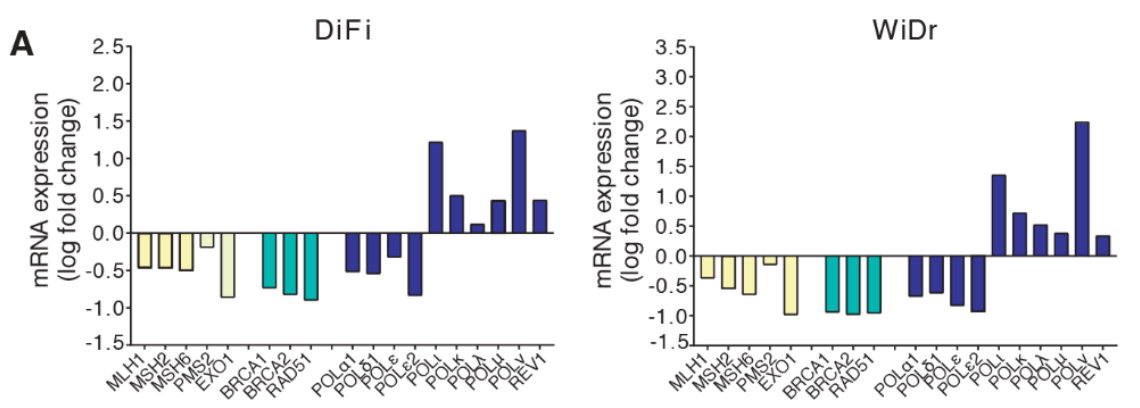

B
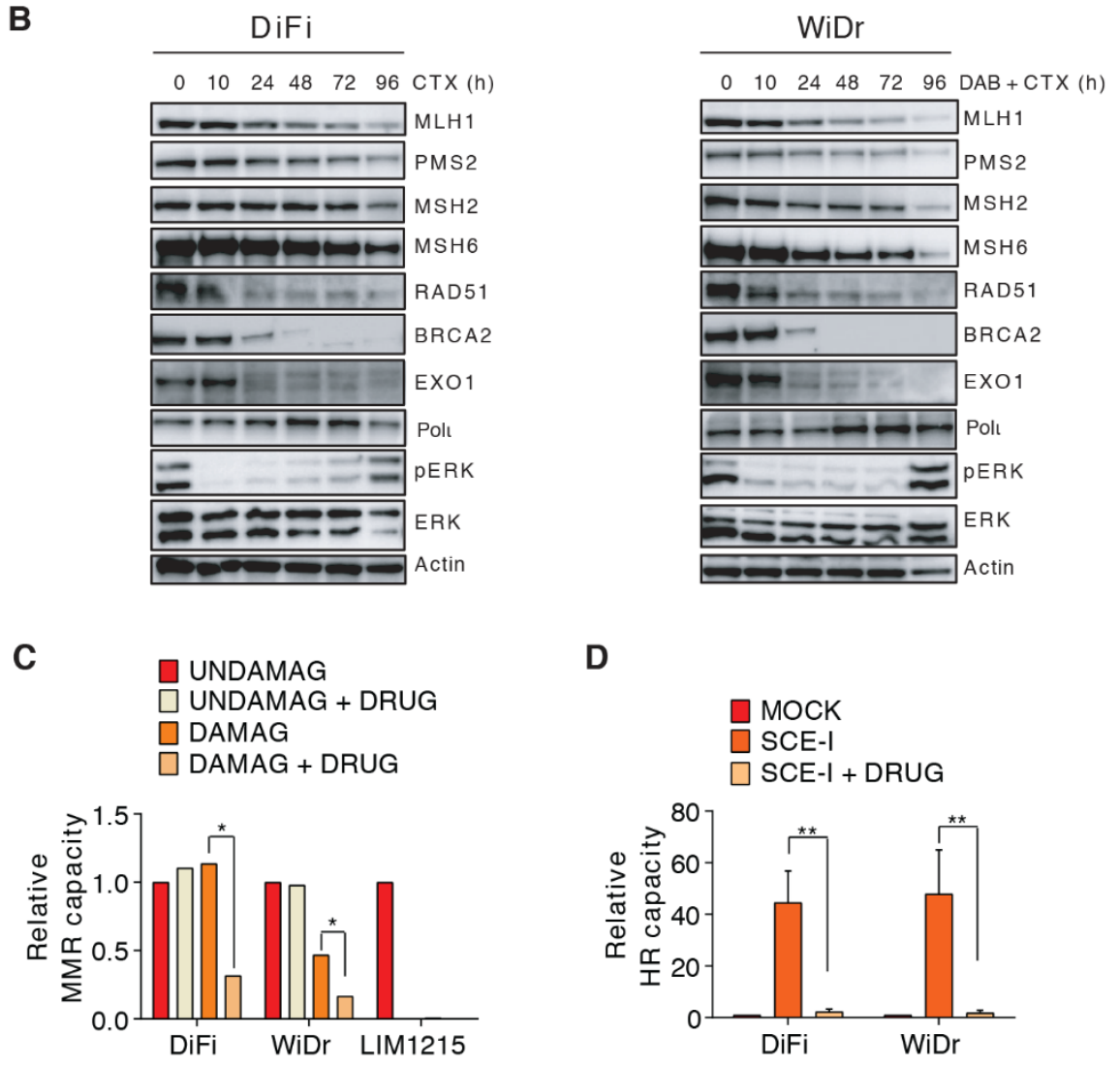

Fig. 1. CRC cells modulate DNA repair effectors in response to targeted agents. (A) CRC cells were treated with cetuximab alone (DiFi) or in combination with the BRAF inhibitor dabrafenib (WiDr) for 96h and RNAseq analysis was performed. Mismatch repair (MMR) (yellow), homologous recombination (HR) (green), and DNA polymerases (blue) genes are reported. Results represent means of two independent experiments. (B) CRC cells were treated and analyzed at indicated time points by Western blot. (C) CRC cells were transfected with G:C undamaged (UNDAMAG) plasmid or with G:G mismatch-damaged (DAMAG) plasmid. Where indicated (DRUG), cells were treated with targeted therapies for fifty-sixty hours and analyzed by flow cytometry. A mock transfection was used as control. Quantification of MMR capacity of each cell line relative to control is reported in the bar graph. MMR deficient CRC cells LIM1215 were used as a positive control for MMR loss. Results represent means of two independent experiments. ${ }^{*} p<0.05$ (Student's $t$ test). (D) pDRGFP-stably expressing CRC cells were transfected with the pCBASce-I plasmid and then either left in the absence of drug or treated with targeted therapies for fifty-sixty hours and analyzed by flow cytometry. A mock transfection was used as control. Quantification of HR capacity of each cell line relative to mock is reported in the bar graph. Results represent means $\pm \mathrm{SD}(\mathrm{n}=3) .{ }^{* *} \mathrm{p}<0.01$ (Student's $t$ test). 
A

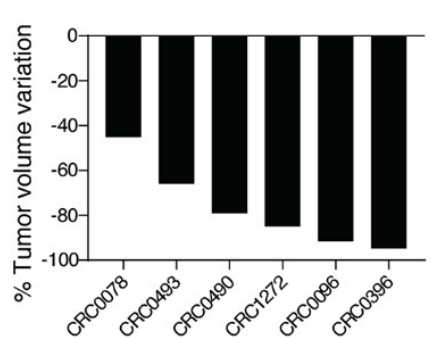

B
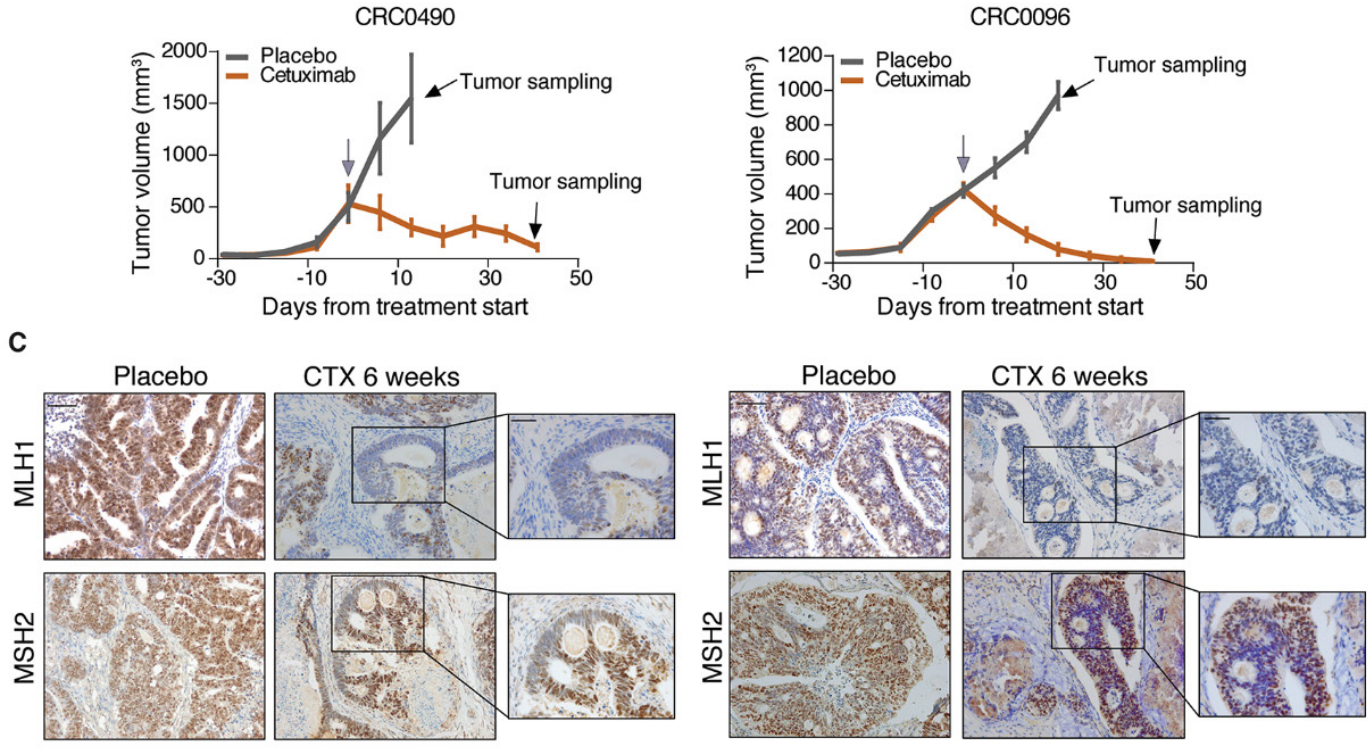

D
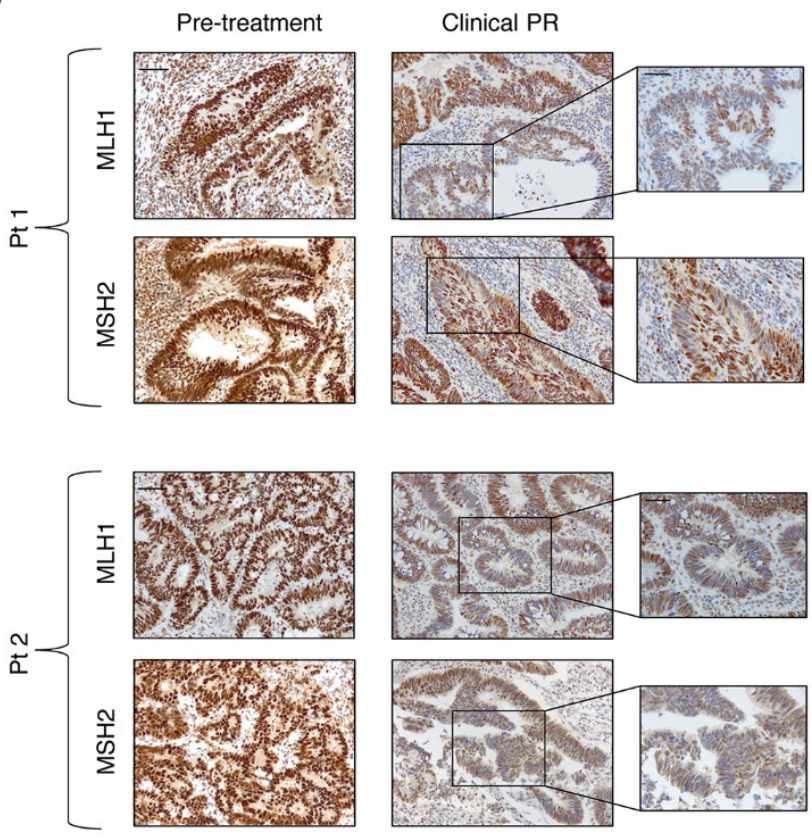

Fig. 2. MMR down-regulation in CRC PDXs and patients treated with targeted therapies. (A) Extent of tumor regression in PDX models after treatment with cetuximab $(20 \mathrm{mg} / \mathrm{kg}$ twice weekly) for six weeks. Each bar is the average of tumor volumes from 6 mice. (B) Growth curve kinetics in two out of six PDXs. Mean tumor volumes \pm SEM $(n=6)$. Gray arrows, treatment initiation. (C) Immunohistochemical staining with anti-MLH1 and anti-MSH2 antibodies of histologic tumor sections derived from indicated PDXs treated with cetuximab for six weeks. Tumor section derived from placebo arm was used as control. Scale bar $0.1 \mathrm{~mm}$. Magnifications $\times 40$ (scale bar $0.05 \mathrm{~mm}$ ). (D) Immunohistochemical staining with anti-MLH1 and anti-MSH2 antibodies of tumor sections derived from two CRC patients treated with FOLFOX+anti-EGFR monoclonal antibody panitumumab. Tumor sections were derived from the primary lesion at diagnosis (pre-treatment), and at the time of partial response (PR) when the lesions shrank. Scale bar $0.1 \mathrm{~mm}$. Magnifications $\times 40$ (scale bar $0.05 \mathrm{~mm}$ ). 
A

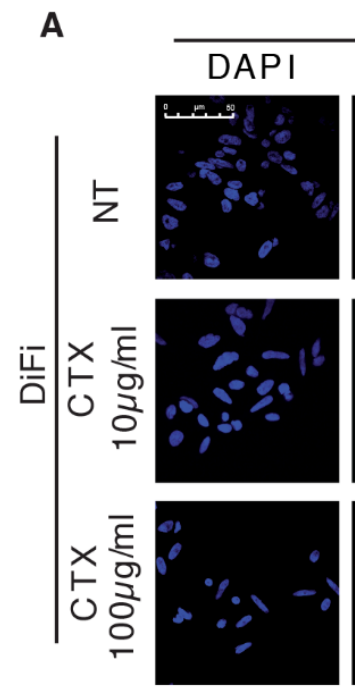

B

DiFi

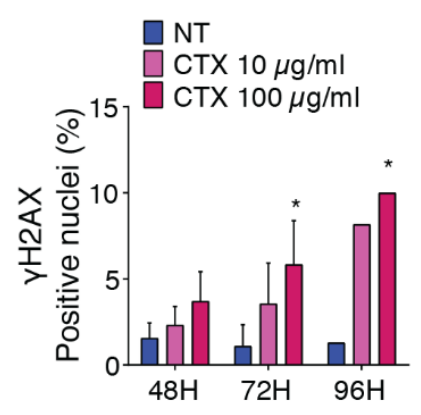

D

DiFi

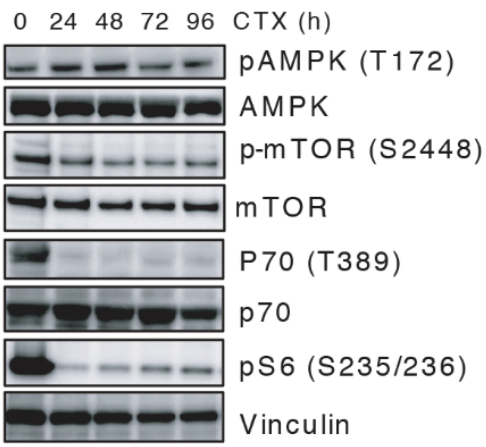

WiDr

$\begin{array}{lllll}0 & 24 & 48 & 72 & 96 \\ \mathrm{DAB} & +\mathrm{CTX}(\mathrm{h})\end{array}$

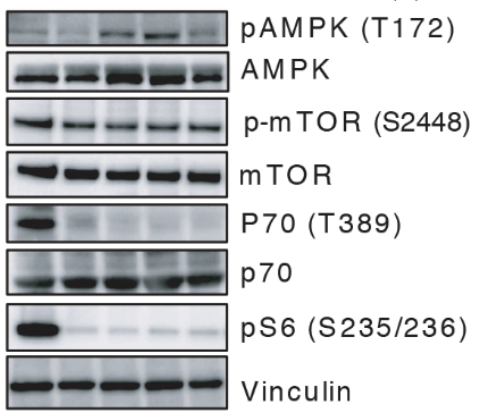

$96 \mathrm{H}$
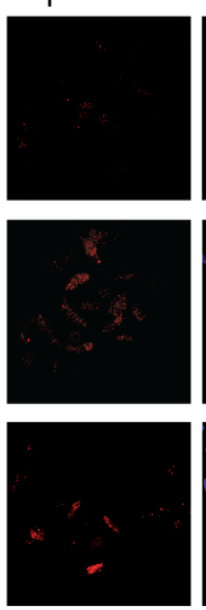

MERGE
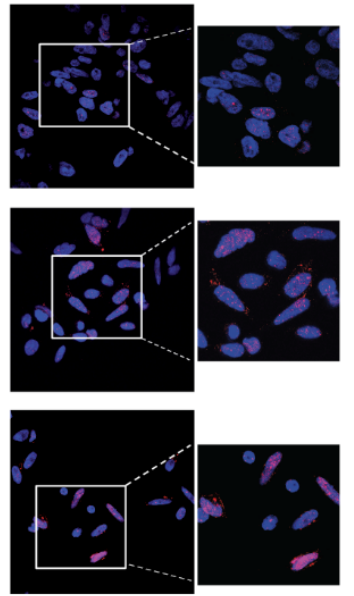

WiDr

NT

DAB 250nM + CTX

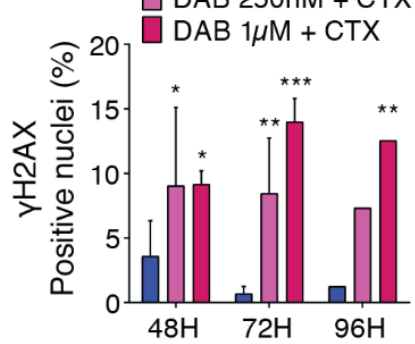

E

DiFi

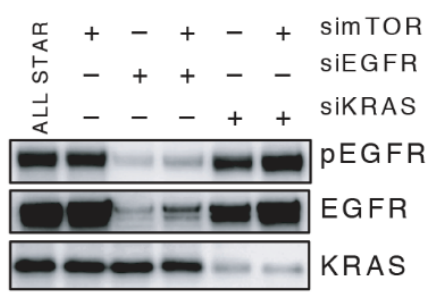

- - - D TOR (S2448)

- - - m mTOR

- -1 ps6 (S235/236)

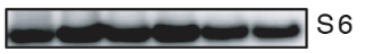

MLH1

-

- $-\cdots \mathrm{MSH}_{2}$

- - - MSH6

RAD51

- - - BRCA2

- EXONO1

-

H2AX

Actin

\begin{tabular}{lll}
\hline DAPI & YH2AX & MERGE
\end{tabular}

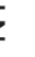
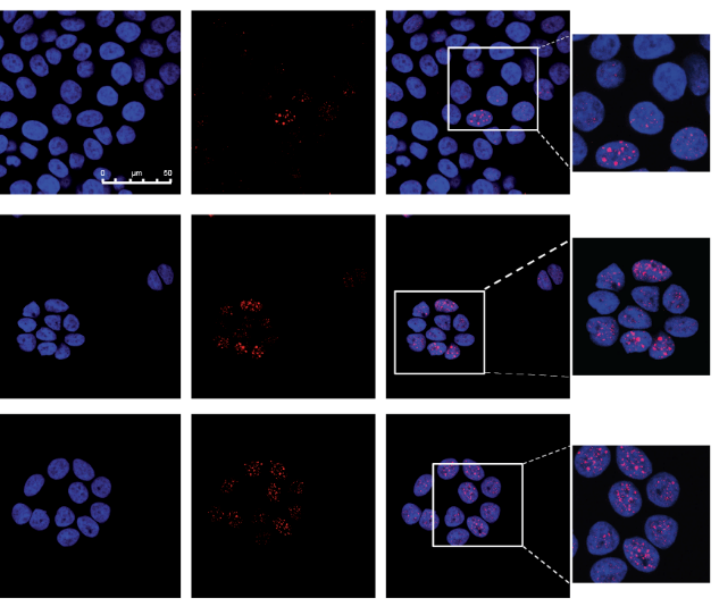

$\mathrm{DiFi}$

WiDr

NT

DAB $1 \mu \mathrm{M}+\mathrm{CTX}$

$N T+N A C$

NT + NAC

DAB $1 \mu \mathrm{M}+\mathrm{CTX}+\mathrm{NAC}$

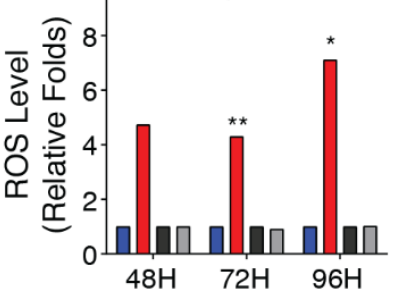

WiDr

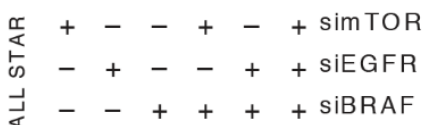

$-m p$ pEGFR

$-\infty \quad-\quad$ EGFR

$\longrightarrow$ BRAF

$\checkmark-\infty-\infty$ p-m TOR (S2448)

Wr-mion

$--\infty$ ps6 (S235/236)

s6

- - - - M M 1

$=-m$ PMS2

-- - - $-\cdots \mathrm{MSH}_{2}$

$------M$ MSH6

$--m-2-m$ RAD51

$-\infty$ BRCA2

$-----\square E X O 1$

$-\cdots \mathrm{pH}_{2 \mathrm{AX}}$

$\longrightarrow$ H2AX

Actin 
Fig. 3. Targeted therapies trigger stress response, increase ROS levels and induce DNA damage in CRC cells. (A) CRC cells were treated as reported and fixed and stained with anti- $\gamma \mathrm{H} 2 \mathrm{AX}$ antibody at indicated time points. Vehicle treated cells (NT) were used as control. Nuclei are stained with DAPI (blue) and anti-үH2AX antibody (red). Scale bar: 50 $\mathrm{mm}$. Representative images for each condition are shown. (B) Quantification of nuclear $\gamma \mathrm{H} 2 \mathrm{AX}$ foci in DiFi (left panel) and WiDr (right panel) cells. Results represent means $\pm \mathrm{SD}$ ( $\mathrm{n}=3$ for 48 and $72 \mathrm{H}$; $\mathrm{n}=2$ for $96 \mathrm{H}$ ). ${ }^{*} \mathrm{p}<0.05$; ${ }^{* *} \mathrm{p}<0.01$; ${ }^{* *} \mathrm{p}<0.001$ (Two Way ANOVA). (C) CRC cells were treated as indicated and ROS levels were measured. NAC was used as a control to rescue ROS production. Results represent means of two independent experiments. ${ }^{*} p<0.05 ;{ }^{* *} p<0.01 ;{ }^{* *} p<0.001$ (Student's $t$ test). (D) CRC cells were treated with targeted therapies and analyzed by Western blot at indicated time points. (E) WT DiFi (left panel) and BRAFmutated WiDr (right panel) cells were transfected with indicated siRNA or combinations of them for 72 hours and analyzed by Western blot. All star, non-targeting siRNA. 
A

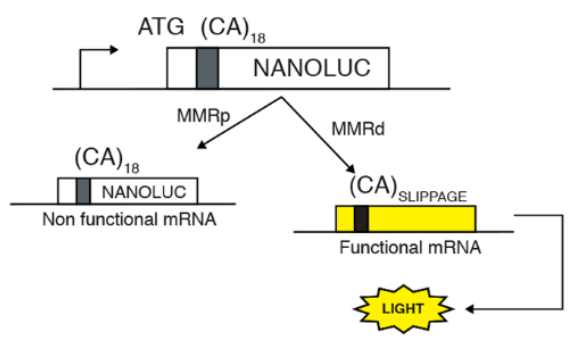

B

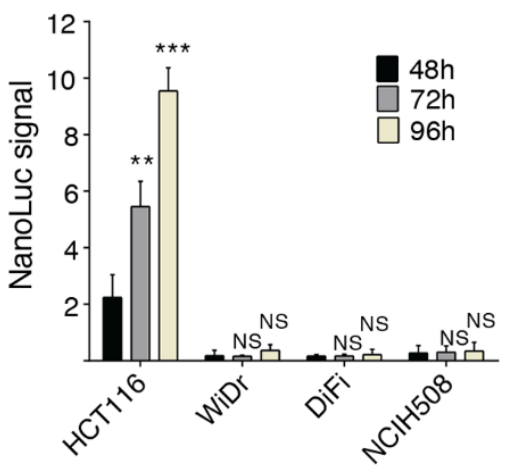

D

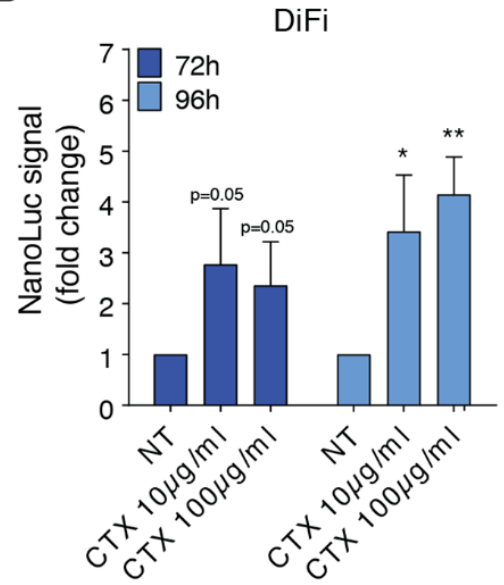

C

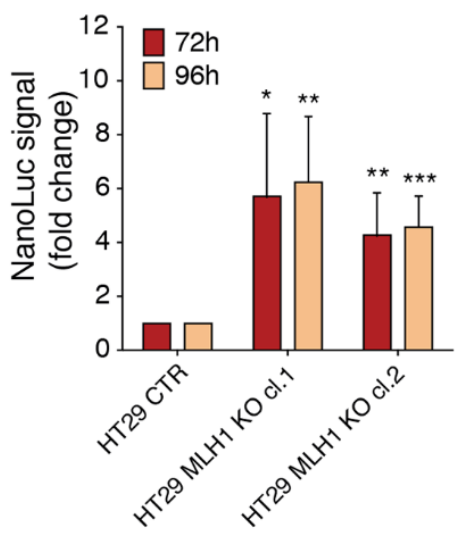

$\mathrm{NCIH508}$

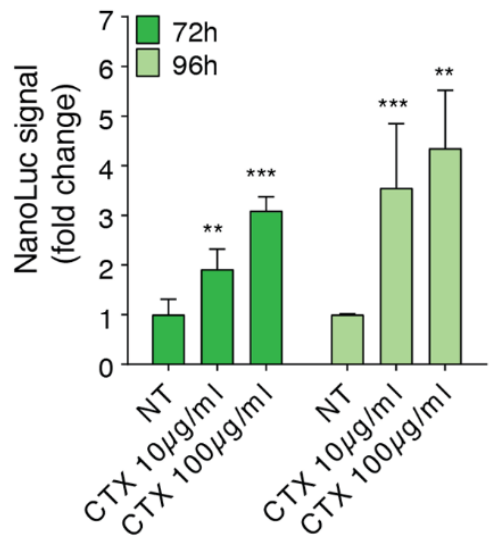

Fig. 4. Treatment with targeted therapies promotes mutagenesis in CRC cells. (A) Schematic representation of the CA-NanoLuc reporter assay. MMRp, mismatch repair proficient; MMRd, mismatch repair deficient. (B) MMRd HCT116 and MMRp DiFi, WiDr and NCIH508 CRC cells were transduced with the NanoLuc lentivirus. At indicated time points NanoLuc signal was evaluated and normalized to cell viability. Results represent means \pm $\mathrm{SD}(\mathrm{n}=3) .{ }^{* *} \mathrm{p}<0.01 ;{ }^{* *} \mathrm{p}<0.001$ (Student's $t$ test). Ns, not statistically significant differences. (C) NanoLuc signal in HT29 MLH1 knock-out (KO) clones (cl. 1 and cl. 2). NanoLuc signal was evaluated after 72 and 96 hours of growth in standard conditions and normalized to cell viability. NanoLuc signal from MLH1 KO clones was then compared to signal detected in MLH1 WT cells (CTR). Results represent means $\pm S D(n=4) .{ }^{*} p<0.05$; ${ }^{* *} p<0.01$; *** $p<0.001$ (Student's $t$ test). (D) DiFi, WiDr, and NCIH508 CRC cells were treated as indicated. NanoLuc signal was normalized to cell viability. NanoLuc signal from treated cells was then compared to signal detected in untreated (NT) cells. Results represent means $\pm S D(n=3) .{ }^{*} p<0.05 ;{ }^{* *} p<0.01 ;{ }^{* * *} p<0.001$ (Student's $t$ test). 
A

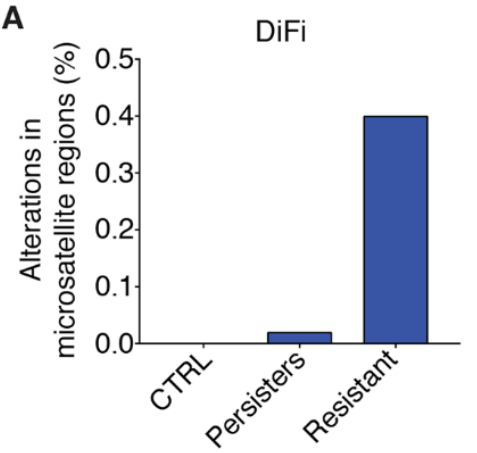

B

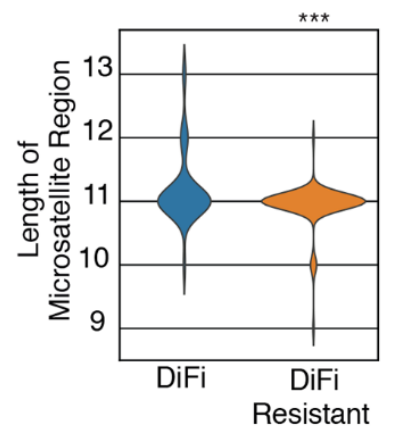

WiDr
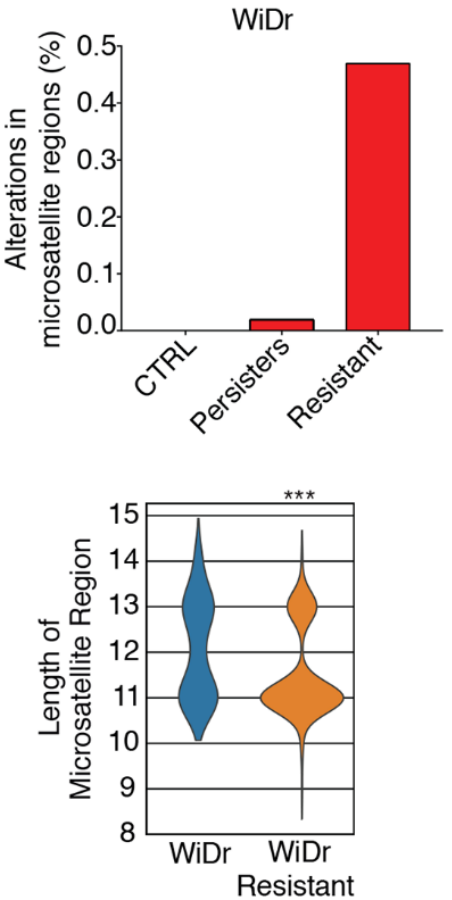

C

WiDr

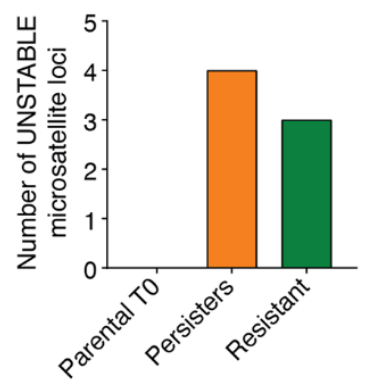

D

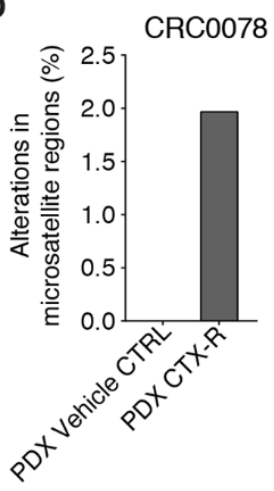

E

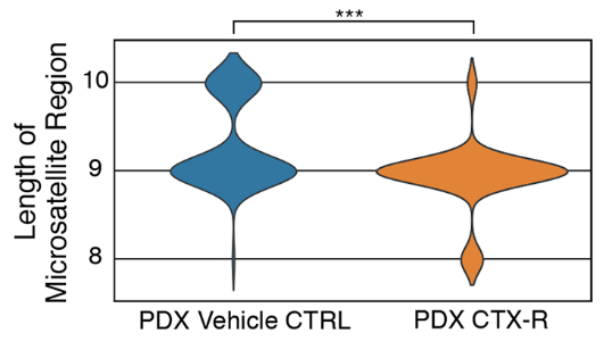

Fig. 5. Adaptive mutability leads to genetic instability in CRC cells in response to therapy-induced stress. (A) Percentage of unstable microsatellite regions in DiFi and WiDr persister and resistant cells compared to their parental counterpart (CTRL). (B) Length distribution of one representative microsatellite region for drugresistant DiFi and WiDr cell lines. ${ }^{* * *} p<0.001$ ( $x 2$ test). (C) Number of unstable microsatellite sites detected by NGS-based high depth capture panel in WiDr cells (parental); treated with cetuximab + dabrafenib for 14 days (persisters) and at resistance. (D) DNA was collected from one vehicle-treated and from one cetuximabresistant PDX. Percentage of unstable microsatellite regions of the tumor collected from the cetuximabresistant mouse (PDX CTX-R) as compared to the vehicle-treated (CTRL) mouse is reported. (E) Length distribution of one representative microsatellite region. ${ }^{* *} p<0.001$ ( $x 2$ test). 